\title{
Production of Resorbable Microparticles Loaded with a Cytostatic Drug Using the Spray-Drying Method and Investigation of Their Properties
}

\author{
Anastasiya V. Murueva* and Anna M. Shershneva \\ Institute of Biophysics of $S B$ RAS \\ 50/50 Akademgorodok, Krasnoyarsk, 660036, Russia
}

Received 18.12.2015, received in revised form 014.01.2016, accepted 21.02.2016

\begin{abstract}
Microparticles of resorbable poly-3-hydroxybutyrate loaded with a cytostatic drug (5-fluorouracil) were prepared by using the spray-drying method. The increase in the level of drug loading from 1 to $10 \%$ of the polymer mass did not significantly effect the average diameter of microparticles $(2.4-$ $2.6 \mu \mathrm{m}$ ) but increased their $\xi$-potential (from 106 to $86 \mathrm{mV}$ ). Encapsulation efficiency of 5-fluorouracil increased with the increase in the level of drug loading. Investigation of the in vitro drug release behavior showed that the total drug release from the microparticles into the medium increased with the growth of mass concentration of the drug (55,63 and $75 \%$ of the initial drug content and 1, 5 and $10 \%$ of the polymer mass, respectively). The cytotoxic effect of encapsulated 5-fluorouracil was proved in the HeLa tumor cell culture.
\end{abstract}

Keywords: drug delivery systems, polyhydroxyalkanoates, spray drying, microparticles, 5-fluorouracil, cytotoxicity.

DOI: $10.17516 / 1997-1389-2015-9-1-75-87$.

(C) Siberian Federal University. All rights reserved

* Corresponding author E-mail address: goreva_a@mail.ru 


\section{Получение резорбируемых микрочастиц, содержащих цитостатический препарат, методом распылительного высушивания и исследование их свойств}

А.В. Муруева, А.М. Шершнева Институт биофизики СО РАН Россия, 660036, Красноярск, Академгородок, 50

С применением метода распылительного высушивания получены микрочастицы из резорбируемого поли-3-гидроксибутирата П(ЗГБ), содержащие противоопухолевый препарат 5-фторурацил. Показано, что увеличение содержания лекарственного препарата от 1 до $10 \%$ от массы полимерного матрикса не оказывало существенного влияния на средний диаметр микрочастиц (2,4 - 2,6 мкм), однако привело к незначительному увеличению $\xi$-потенциала (от -106 до -86 мВ). Эффективность инкапсулирования 5-фторурачила возрастала с увеличением содержания препарата в матриксе микрочастии. Выход 5-фторурацила в фосфатный буфер возрастал с увеличением содержания препарата в матриксе микрочастии и составил 55, 63 и $75 \%$ при исходном содержании препарата, равном 1, 5 и $10 \%$ соответственно. Антипролиферативное действие депонированного 5-фторурацила доказано в культуре опухолевых клеток HeLa.

Ключевые слова: системы доставки лекарственных средств, полигидроксиалканоаты, распылительное высушивание, микрочастицы, 5-фторуращил, цитотоксичность.

\section{Введение}

В настоящее время фармацевтическая индустрия разрабатывает полимерные системы для доставки лекарств, используемых при лечении различных заболеваний. Использование новых лекарственных форм позволяет устранить многие недостатки традиционных лекарственных форм. Системы доставки лекарств на основе полимерных микрочастиц способствуют повышению терапевтического эффекта и снижению токсичности лекарственного препарата по сравнению с его свободной формой (Ambruosi et al., 2006).

Разработка полимерных лекарственных форм ведется в основном с применением биорезорбируемых полимеров - полилактидов, полигликолидов и их сополимеров, а также полиэфиров алкановых кислот микробиологического происхождения - полигидроксиалканоатов (ПГА).

Наиболее популярным методом получения микрочастиц из ПГА является микроэмульсионный метод (или метод испарения/ экстракции растворителя) (Emblenton et al., 1992; Lassalle et al., 2007; Freitas et al., 2005; Bazzo et al., 2009). Представительная серия публикаций по конструированию и исследованию свойств микрочастиц из ПГА принадлежит коллективу сотрудников Института биофизики СО РАН и Сибирского федерального университета. К настоящему моменту с применением микроэмульсион- 
ного метода получено и всесторонне исследовано семейство микрочастиц от 0,3 до 100 мкм; показана возможность нагружения антибактериальными и цитостатическими препаратами и длительной кинетики оттока препаратов in vitro. Доказана биологическая безопасность и лекарственная эффективность микрочастиц из ПГА в культурах клеток и в экспериментах на животных (Shishatskaya et al., 2011, 2013; Goreva et al., 2012; Murueva et al., 2013).

Полимерные микроносители в виде микро- и наночастиц, содержащих различные лекарственные препараты, могут быть получены с помощью метода фазового разделения (коацервация), полимеризации мономеров, гранулирования. По сравнению с вышеперечисленными методами распылительная сушка является наиболее простым, недорогим и производительным способом получения микрочастиц (Daugherty et al., 2006; Vehring, 2008; Ramezani et al., 2013; Anchordoquy et al., 2000). В настоящее время методом распылительного высушивания получены и исследованы микрочастицы из различных материалов - сахаров дигидрата трегалозы и D(-)маннита (Lebrun et al., 2012); иммуноглобулина (IgG) человека (Mw 15 кДа), стабилизированного дигидратом трегалозы и D(-)маннитом (Ramezani et al., 2013); сополимера молочной и гликолевой кислот (ПМГК) (Jensen et al., 2010); гибридов ПМГК с coeвым лецитином (Wang et al., 2012); микрофибриллированной целлюлозы (Kolakovic et al., 2012); низкомолекулярного хитозана (Mohajel et al., 2012). С применением метода распылительного высушивания получены микрочастицы из полилактида и сополимера полилактид-гликолид, содержащие противоопухолевый препарат 5-фторурацил, антибиотики рифампицин, офлоксацин (Blanco et al., 2005; Ohashi et al., 2009; Palazzo et al.,
2013); хитозановые микрочастицы с метотрексатом, ацикловиром (Stulzer et al., 2009); лактозные микрочастицы с флюрбипрофеном и этензамидом.

В современной литературе не представлено работ по изучению возможности применения метода распылительной сушки для конструирования микро- и наночастиц из ПГА, содержащих лекарственные препараты. Ранее нами было показано, что этот метод может быть успешно применен для конструирования микрочастиц на основе поли-3-гидроксибутирата (П(ЗГБ)). Установлены зависимости характеристик микрочастиц (выход, средний диаметр, дзета-потенциал) от параметров процесса получения (температура на входе в систему, скорость подачи полимерного раствора и концентрация раствора полимера) (Шершнева и др., 2014).

Цель настоящей работы - конструирование микрочастиц из ПГА, содержащих противоопухолевый препарат 5-фторурацил, методом распылительного высушивания и исследование их свойств, включая кинетику выхода и цитотоксического действия препарата в культуре клеток карциномы шейки матки человека (HeLa), в сравнении с традиционной лекарственной формой.

\section{Материалы и методы}

Для получения микрочастиц использованы высокоочищенные образцы поли-3гидроксибутирата (П(ЗГБ)), синтезированного по разработанной технологии (Волова и др., 2001). С применением набора деполимеризующих реагентов были получены образцы П(ЗГБ) с молекулярной массой 6 кДа. Средневесовую $\left(\mathrm{M}_{\mathrm{w}}\right)$ и среднечисловую молекулярную массу $\left(\mathrm{M}_{\mathrm{n}}\right)$ и молекулярномассовое распределение ПГА исследовали с использованием хроматографа для гель- 
проникающей хроматографии 1260 Infinity (Agilent Technologies, США).

Микрочастицы из П(ЗГБ) получены в установке Mini Spray Dryer B-290 (BUCHI Laboratory Equipment, Швейцария), оснащенной соплом распылителя (отверстие диаметром 0,7 мм), через которое подается инертный газ (аргон) и с током газа под действием центробежных сил сухие частицы осаждаются в высокопроизводительные циклоны. Температура на входе в систему составила $95{ }^{\circ} \mathrm{C}$, скорость подачи полимерного раствора - 1,5 мл/мин, величина аспиратора (ток газа) имела максимальный расход газа и составляла $35 \mathrm{~m}^{3} / \mathrm{q}$.

Для отработки техники депонирования препарата в полимерные микрочастицы с использованием метода распылительного высушивания был взят противоопухолевый препарат 5-фторурацил (Sigma-Aldrich). Выбор данного лекарственного препарата обусловлен его востребованностью в клинической практике, стабильностью в растворах и возможностью смешения с неполярными растворителями без изменения свойств.

Для нагружения микрочастиц 5-фторурацилом использовали 1,5\%-й раствор П(ЗГБ) в хлороформе. К полученному раствору добавляли определенное количество 5-фторурацила (из расчета 1,5 и $10 \%$ от массы полимерного носителя) и гомогенизировали с помощью ультразвука при мощности 5 Вт в течение 1 мин. Для предотвращения выпадения в осадок 5-фторурацила полученную гомогенную суспензию поддерживали при непрерывном перемешивании на магнитной мешалке (700 об/мин) и распыляли через сопло распылителя при вышеописанных параметрах установки.

Выход микрочастиц рассчитывали в процентах от массы использованного для их получения полимера:

$$
B=\frac{M m \times 100 \%}{M n},
$$

где $M м$ - масса полученных микрочастиц, мг; $M n$ - масса использованного полимера, мг.

Морфологию микрочастиц изучали с применением сканирующего электронного микроскопа ТМ-3000 (Hitachi, Япония). Напыление образцов платиной проводили в установке K575XD Turbo (Emitech, Англия).

Размеры и размерное распределение микрочастиц измеряли на анализаторе частиц Zetasizer Nano ZS (Malvern, Великобритания) с использованием метода динамического светорассеивания. Поверхностный заряд микрочастиц был охарактеризован величиной электрокинетического потенциала (дзета-потенциала), которая определяется электрофоретической подвижностью частиц в суспензии с применением уравнения Генри на анализаторе частиц Zetasizer Nano ZS. Измерения проводили в автоматическом режиме по стандартной методике, рекомендуемой производителем.

Величину включения 5-фторурацила в полимерную матрицу определяли по его исходной и остаточной концентрации в эмульсии, которую находили спектрофотометрически при излучении на длине волны 265 нм (спектрофотометр Cary $60 \mathrm{UV}-\mathrm{Vis}$, Agilent Technologies, США).

Эффективность инкапсулирования (Эu) препарата в полимерной матрице рассчитывали по формуле

$$
\ni_{u}=\frac{M_{\text {инк }} \times 100 \%}{M u c x},
$$

где Минк - масса инкапсулированного препарата, мг; Mucx - исходная масса препарата, мг.

Полученные из П(ЗГБ) микрочастицы, нагруженные 5-фторурацилом (навеска микро- 
частиц 15 мг), стерилизовали УФ-излучением в течение 40 мин и помещали в стерильные центрифужные пробирки с крышкой $(\mathrm{n}=3)$ в 7 мл сбалансированного фосфатного буфера (СФБ); пробирки экспонировали в термостате при $37^{\circ} \mathrm{C}$ в течение 15 сут. Для определения количества препарата, вышедшего в среду, из пробирок отбирали пробы, в которых, предварительно осадив микрочастицы центрифугированием (10 000 об/мин, 5 мин), спектрофотометрически измеряли концентрацию 5-фторурацила.

Выход препарата в СФБ определяли так:

$$
D R=\frac{r}{e} \cdot 100 \%
$$

где $e$ - количество инкапсулированного в полимерной матрице препарата, мг/мл; $r$ - выход препарата, мг/мл.

Анализ полученных экспериментальных данных по выходу лекарственного препарата в среду и определение значений коэффициента диффузии в полимерной фазе выполнен путем графического решения уравнений, предложенных ранее в работах (Livshits et al., 2009; Goreva et al., 2012).

Эффективность действия разработанных препаратов оценена в культуре опухолевых клеток карциномы шейки матки человека HeLa. Клетки HeLa помещали в культуральные планшеты из расчета 5-10 × 104 клеток/ мл в каждую лунку. В качестве среды использовали DMEM, содержащую 10\%-й раствор эмбриональной бычьей сыворотки и раствор антибиотиков (стрептомицин 100 мкг/мл, пенициллин 100 ЕД/мл). Для эксперимента были приготовлены полимерные микрочастицы из П(ЗГБ) с различной нагрузкой цитостатика. Суспензию стерильных частиц в 100 мкл фосфатного буфера вводили в каждую лунку 24-луночного планшета. При внесении микрочастиц в культуру клеток в виде суспензии концентрация инкапсулированного 5-фторурацила составила: 0,$6 ; 1,3 ; 6,5$ мг/мл. В качестве положительного контроля использовали культуры клеток с добавлением свободного препарата в аналогичной концентрации. Культивирование проводили в $\mathrm{CO}_{2}$-инкубаторе (New Brunswick Scientific, США) в 5\%-й атмосфере $\mathrm{CO}_{2}$ при $37^{\circ} \mathrm{C}$. Смену среды проводили каждые 24 ч в течение 3 сут. Жизнеспособность клеток HeLa оценивали с помощью МТТ-теста.

Статистическую обработку результатов проводили с использованием стандартного пакета программ Microsoft Excel.

\section{Результаты и обсуждение}

Получение и исследование

свойств микрочастии из П(ЗГБ),

содержащих 5-фторурачил

В работе впервые применен метод распылительного высушивания для получения микрочастиц из П(ЗГБ), содержащих противоопухолевый препарат 5-фторурацил, с использованием специализированной установки для распылительного высушивания.

При депонировании в полимерную матрицу микрочастиц 5-фторурацила не обнаружено существенных изменений в поверхностной структуре частиц по сравнению с микрочастицами, не содержащими лекарственный препарат. Так, микрочастицы, нагруженные 5-фторурацилом, имели сферическую форму с шероховатой поверхностью (рис. 1). На микрофотографиях отмечено присутствие крупных дефектных частиц, однако их количество составило $1 \%$ от общего количества микрочастиц. Неправильная форма крупных частиц может быть связана с образованием достаточно крупных полимерных капель, которые под действием высокого давления и температуры лопались, проходя через сушильную камеру. Известно, что микрочастицы, полученные с 


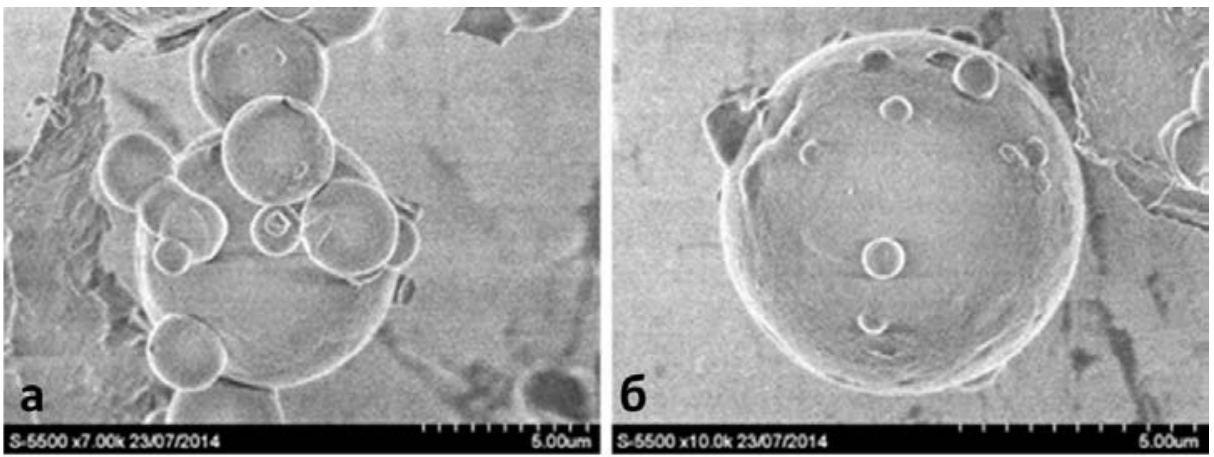

Рис. 1. РЭМ-снимки микрочастиц, полученных из П(ЗГБ) (а), и микрочастиц из ПЗГБ, содержащих 5-фторурацил (б). Маркер 5 мкм

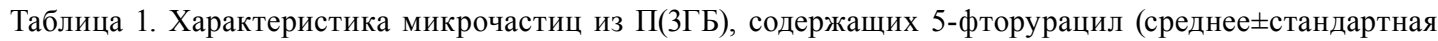
ошибка, $\mathrm{n}=3$ )

\begin{tabular}{|c|c|c|c|c|}
\hline $\begin{array}{c}\text { Состав } \\
\text { микрочастиц }\end{array}$ & $\begin{array}{c}\text { Средний диаметр, } \\
\text { мкм }\end{array}$ & $\begin{array}{c}\text { Дзета-потенциал, } \\
\text { мB }\end{array}$ & $\begin{array}{c}\text { Эффективность } \\
\text { инкапсулирования, \% }\end{array}$ & Выход, \% \\
\hline П(ЗГБ) & $2,7 \pm 0,4$ & $-102 \pm 2,0$ & - & $71 \pm 5,6$ \\
\hline П(ЗГБ)-(1 \% 5-ФУ) & $2,6 \pm 0,1$ & $-106 \pm 9,9$ & $48 \pm 0,5$ & $65 \pm 6,8$ \\
\hline П(ЗГБ)-(5 \% 5-ФУ) & $2,6 \pm 0,2$ & $-83 \pm 0,8$ & $56 \pm 0,6$ & $67 \pm 7,6$ \\
\hline $\begin{array}{l}\text { П(3ГБ)-(10 \% } \\
5-Ф У)\end{array}$ & $2,5 \pm 0,1$ & $-86 \pm 1,6$ & $57 \pm 0,5$ & $78 \pm 7,7$ \\
\hline
\end{tabular}

помощью метода распылительного высушивания, полые внутри и могут содержать более мелкие микрочастицы в своей внутренней полости (Mohajel et al., 2012; Шершнева и др., 2014).

Увеличение содержания 5-фторурацила в полимерной матрице микрочастиц (от 1 до $10 \%$ от массы полимерной основы) не оказывало существенного влияния на диаметр микрочастиц. При этом величина электрокинетического потенциала с увеличением содержания 5-фторурацила незначительно возрастала (табл. 1). Средний диаметр микрочастиц с депонированным 5-фторурацилом был сопоставим с диаметром микрочастиц, не содержащих лекарственный препарат, и составил 2,5-2,6 мкм. Возможно, это связано с тем, что 5-фторурацил имеет низкое значение молекулярной массы (130 г/моль) и не оказывает влияния на укладку полимерных цепей в процессе формирования частиц.

Дзета(乡)-потенциал является важной характеристикой микрочастиц, определяющей электрокинетическое взаимодействие между частицами, приближение к нулевому значению которого позволяет частицам сближаться друг с другом и флоккулировать. Наиболее высокий $\xi$-потенциал зарегистрирован у микрочастиц с содержанием 5-фторурацила 5 и $10 \%$ от массы полимерного матрикса; он составил -83 и -86 мВ соответственно. Более низкие значения $\xi$-потенциала были зафиксированы для микрочастиц с содержанием 5-фторурацила 1 \% и составили -106 мВ. Таким образом, величина $\xi$-потенциала у микрочастиц, полученных методом распылительного высушивания, в том числе нагруженных лекарственным препаратом, варьи- 
ровала в достаточно узком диапазоне от -86 до -106 мВ. Это свидетельствует о том, что нагружение микрочастиц 5-фторурацилом не оказывает существенного влияния на форму полученных микрочастиц и подтверждает физическую стабильность образцов.

Эффективность инкапсулирования препаратов в матрицу микрочастиц (Эu) зависела от массовой доли препарата в исходном полимерном растворе (табл. 1). При увеличении содержания 5-фторурацила в микрочастицах зафиксировано увеличение эффективности инкапсулирования препарата. Аналогичные зависимости были показаны для полимерных микрочастиц из ПГА, полученных эмульсионным методом, содержащие противоопухолевые препараты доксорубомицин, 5-фторурацил (Murueva et al., 2013; Khang et al., 2001). Так, при 1\%-м содержании 5-фторурацила Эи составила $47,6 \pm 0,5$ \%, тогда как при увеличении до $10 \%$ - повысилась до $57 \pm 0,5 \%$.

Выход микрочастиц, нагруженных 5-фторурацилом, был сопоставим с выходом, полученным для микрочастиц, не содержащих лекарственный препарат ( 70 \%).

\section{Исследование динамики}

выхода 5-фторурацила

из П(ЗГБ) микрочастии in vitro

Анализ литературных данных свидетельствует о том, что выход лекарственных препаратов из полимерных систем пролонгированного действия может быть реализован с помощью диффузии, при которой препараты перемещаются к краю полимерного изделия и затем переходят во внешнюю среду (Burgess, 2005). Известно, что П(ЗГБ) в условиях in vitro при отсутствии биологических факторов (ферменты, клетки) не гидролизуется с разрывом углеродной цепи (Holland et al., 1990), поэтому выход препаратов из носителей П(ЗГБ) реализуется по законам химических реакций и не зависит от состояния материала носителя.

Полученные экспериментальные кривые выхода 5-фторурацила из микрочастиц в среду представлены на рис. 2. Результаты показывают, что первая фаза выхода 5-фторурацила из полимерных микрочастиц характеризуется сравнительно быстрым высвобождением препарата в среду (на 4-е сутки),

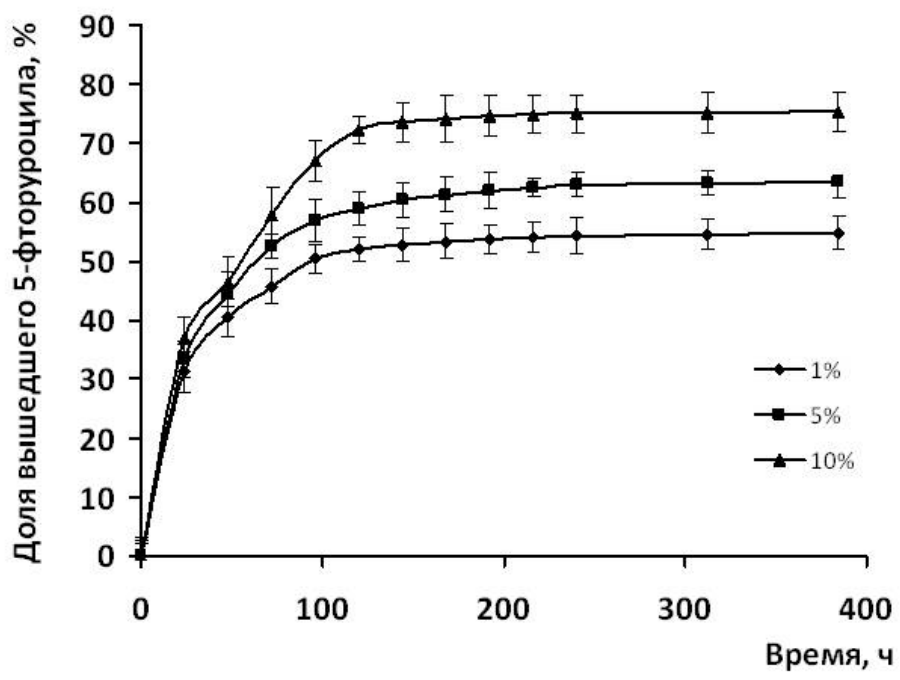

Рис. 2. Динамика выхода 5-фторурацила из П(3ГБ) микрочастиц, в разной степени нагруженных цитостатиком $(1,5$ и $10 \%$ от массы полимерного матрикса) 
что, по-видимому, объясняется присутствием большого количества лекарства на поверхности микрочастиц и слабым гидрофобным взаимодействием между препаратом и полимером. На следующей фазе высвобождения 5-фторурацила (на 5-6-е сутки) преобладают диффузионные механизмы, связанные с выделением препарата из внутренних структур матрицы, в том числе в результате медленного и незначительного изменения молекулярной массы полимера, поэтому концентрация препарата в модельной среде становится практически постоянной.

На кинетику выхода 5-фторурацила оказывала влияние степень нагруженности микрочастиц. Как показано на рис. 2, выход 5-фторурацила из П(3ГБ) микрочастиц был тем выше, чем больше была величина включения препарата в матрицу. При максимальной и минимальной нагруженности матрицы в первые сутки выход препарата составил $31 \pm 2,5$ и $37 \pm 3 \%$ (от включенного) соответственно. Однако начиная с 5-х суток кривые вышли на плато. Далее концентрация 5-фторурацила в фосфатном буфере практически не изменялась. К концу эксперимента в модельной среде было зарегистрировано следующее содержание цитостатика: $55 \pm 2,8,63 \pm 3,0$ и 75 $\pm 3,5$ \% при исходном нагружении микрочастиц на 1, 5 и 10 \% (от массы полимерного носителя) соответственно.

Первая фаза высвобождения 5-фторурацила характеризуется диффузионным механизмом выхода препарата с поверхности полимерной матрицы. Вторая фаза связана с выходом препарата из внутренних структур матрицы и началом гидролитических процессов в микропористой среде и характеризуется реакцией нулевого порядка. Двустадийный характер выхода 5-фторурацила из П(ЗГБ) микрочастиц можно описать диффузионно кинетическими уравнениями, предложенны- ми ранее в работах (Livshits et al., 2009; Goreva et al., 2012).

$$
\frac{\partial c_{s}}{\partial t}=D_{s}\left(\frac{\partial^{2} c_{s}}{\partial x^{2}}\right)+K
$$

где $\mathrm{D}_{\mathrm{s}}$ - эффективный коэффициент диффузии $\mathrm{cm}^{2} / \mathrm{c} ; \mathrm{K}$ - кинетическая константа гидролитической деструкции полимера, $\mathrm{c}^{-1}$; $\mathrm{c}_{\mathrm{s}}$ - концентрация антибиотика,\%; $\partial \mathrm{c}_{\mathrm{s}} / \partial \mathrm{t}$ и $\partial^{2} \mathrm{c}_{\mathrm{s}} / \partial \mathrm{x}^{2}-$ первая и вторая производная по координате диффузии

Чтобы исключить влияние линейного вклада, обусловленного незначительным понижением молекулярной массы полимера, из суммарной концентрации вышедшего цитостатика введена переменная

$$
G_{t}=c_{s}-K \times t,
$$

здесь Gt - количество антибиотика (\%), вышедшего по диффузионному механизму за время t. Тогда диффузионно-кинетическое уравнение приобретает традиционный вид:

$$
\frac{\partial c_{s}}{\partial t}=D_{s}\left(\frac{\partial^{2} c_{s}}{\partial x^{2}}\right)
$$

При отсутствии концентрационной разницы на границе раздела твердая частицажидкая фаза последнее уравнение характеризует механизм десорбции препарата из микрочастицы.

В случае малого времени десорбции антибиотика на начальном уровне $\mathrm{m}_{\mathrm{t}} / \mathrm{m}_{\infty} \leq 0,5$ выход препарата можно описать уравнением Фика:

$$
\frac{m_{t}}{m_{\infty}}=\sqrt[4]{\frac{D t}{\pi h^{2}}}
$$

где $\frac{m_{t}}{m_{\infty}}-$ суммарный выход препарата в момент времени $\mathrm{t}\left(\mathrm{m}_{\mathrm{t}}\right)$ и при бесконечном вре- 
мени $\mathrm{t} \rightarrow \infty\left(\mathrm{m}_{\infty}\right)$; Dt - коэффициент диффузии; $\mathrm{h}$ - толщина матрицы.

Учитывая, что частицы имеют сферическую форму, толщина матрицы (h) может быть заменена на диаметр частицы (d), тогда

$$
\frac{m_{t}}{m_{\infty}}=\sqrt[4]{\frac{D t}{\pi d^{2}}},
$$

где $\mathrm{d}$ - диаметр матрицы (микрочастицы).

Коэффициент диффузии на начальном этапе кривой выхода лекарственного препарата составит:

$$
D_{\beta}=\frac{\pi d^{2} \times(\operatorname{tg} \beta)^{2}}{16},
$$

здесь $\operatorname{tg} \beta$ - тангенс угла наклона прямолинейного участка кинетической кривой в координатах $\left(\mathrm{m}_{\mathrm{t}} / \mathrm{m}_{\infty}\right)-\mathrm{t}^{0.5}$.

Линейные участки кинетических кривых, отображенные в полулогарифмических координатах, позволяют рассчитать тангенс угла наклона $\operatorname{tg} \alpha$, а затем и собственно коэффициент диффузии:

$$
D_{\alpha}=\frac{d^{2}(\operatorname{tg} \alpha)^{2}}{\pi^{2}},
$$

где $\operatorname{tg} \alpha$ - тангенс угла наклона кинетической кривой в полулогарифмических координатах $\ln \left(1-\mathrm{m}_{\mathrm{t}} / \mathrm{m}_{\infty}\right)$

Графическое решение уравнений (9) и (10) в координатах $\left(\mathrm{m}_{\mathrm{t}} / \mathrm{m}_{\infty}\right)-(\mathrm{t})^{0.5}$ и в полулогарифмических координатах $\ln \left(1-\mathrm{m}_{\mathrm{t}} / \mathrm{m}_{\infty}\right)$ позволило количественно определить значение коэффициента диффузии препарата в полимерной фазе (рис. 3).

В табл. 2 представлены полученные коэффициенты диффузии 5-фторурацила в микрочастицах из П(ЗГБ). Из приведенных данных видна четкая зависимость коэффициентов диффузии от содержания препарата в полимерном матриксе. Так, коэффициент диффузии на первом этапе для микрочастиц с максимальным содержанием цитостатика в 3,5 раза больше по сравнению с микрочастицами с минимальным содержанием лекарственного препарата (табл. 2, уравнение (9)). На втором этапе (соответствует выходу кривой на плато) коэффициент диффузии падает на порядок независимо от степени нагруженности микрочастиц 5-фторурацилом.

Полученные результаты свидетельствуют о классическом диффузионном механизме, определяющем кинетику выхода 5-фторурацила из полимерных микрочастиц на основе П(ЗГБ).

\section{Исследование антипролиферативного} действия микрочастии, содержащчих 5-фторурацил

Результаты исследования антипролиферативного действия микрочастиц из П(ЗГБ), нагруженных 5-фторурацилом, на культуру опухолевых клеток HeLa по сравнению со свободной формой препарата представлены на рис. 4.

Антипролиферативное действие депонированного 5-фторурацила отмечено уже на первые сутки, и при этом оно было сопоставимо с действием свободного препарата. Однако начиная со вторых суток независимо от концентрации лекарственного препарата цитостатический эффект депонированного 5-фторурацила был более выражен по сравнению со свободным препаратом. Частицы, нагруженные в самой меньшей степени (0,6 мг/мл), по сравнению со свободной формой цитостатика эффективно подавляли рост опухолевых клеток, количество которых к третьим суткам эксперимента составило $0,26 \times 10^{5} /$ мл. Максимальное подавление роста клеток HeLa на 3-и сутки было при использовании микрочастиц, нагруженных 5-фторурацилом в концентрации 6,5 мг/мл; в этом варианте концен- 

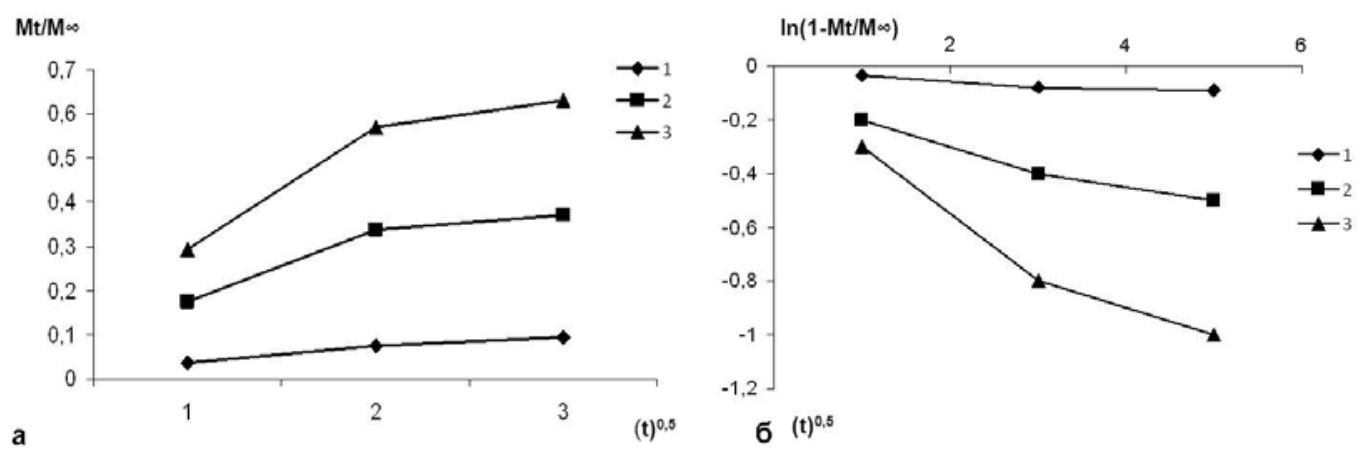

Рис. 3. Начальные (а) и конечные участки (б) кинетической кривой, иллюстрирующей выход 5-фторурацила из П(ЗГБ) микрочастиц. Содержание 5-фторурацила: 1 - 1 \%; 2 - 5 \%; 3 - 10 \%

Таблица 2. Коэффициенты диффузии 5-фторурацила в микрочастицах из П(ЗГБ), определяющие начальную и конечную фазы диффузионного процесса

\begin{tabular}{|c|c|c|}
\hline \multirow{2}{*}{ Состав микрочастиц } & \multicolumn{2}{|c|}{ Коэффициент диффузии } \\
\cline { 2 - 3 } & $\mathrm{D}^{*} 10^{-10} \mathrm{~cm}^{2} / \mathrm{c}($ Уравнение 9) & $\mathrm{D}^{*} 10^{-10} \mathrm{~cm}^{2} / \mathrm{c}$ (Уравнение 10) \\
\hline П(ЗГБ)-(1 \% 5-ФУ) & 1,0 & 0,027 \\
П(ЗГБ)-(5 \% 5-ФУ) & 1,2 & 0,025 \\
П(ЗГБ)-(10 \% 5-ФУ) & 3,6 & 0,038 \\
\hline
\end{tabular}

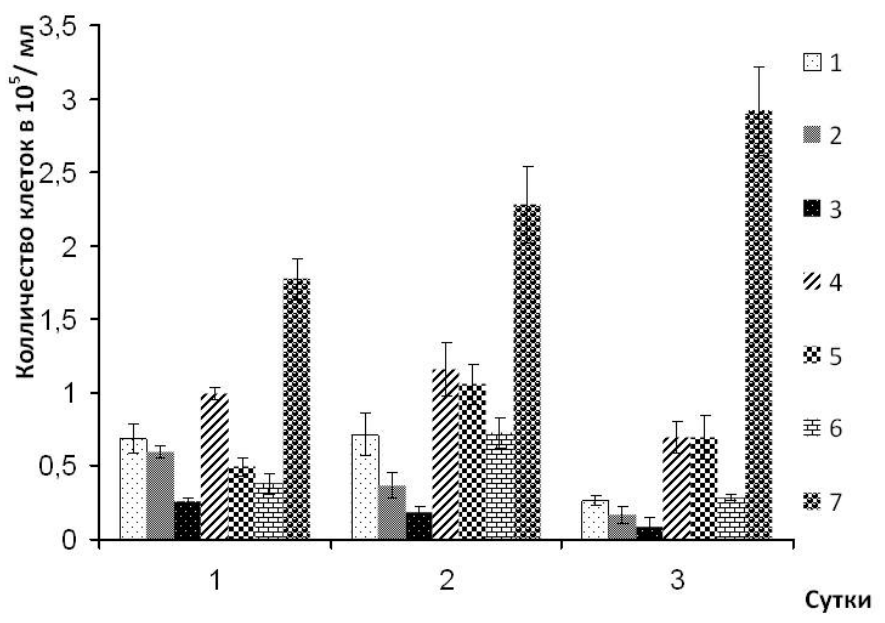

Рис. 4. Количество жизнеспособных клеток в культуре HeLa (по результатам MTT-теста) при добавлении в среду разных концентраций свободного и инкапсулированного 5-фторурацила: 1 - 0,6 мг/л П(ЗГБ)-(1 \% 5-ФУ); 2 - 1,3 мг/л П(ЗГБ)-(5 \% 5-ФУ); 3 - 6,5 мг/л П(ЗГБ)-(10\% 5-ФУ); 4 - 0,6 мг/л 5-ФУ; 5 - 1,3 мг/л 5-ФУ; 6 - 6,5 мг/л 5-ФУ; 7 - контроль

трация клеток составила $0,08 \times 10^{5} /$ мл, в то время как в контрольной группе она достигла $2,9 \times 10^{5} /$ мл.
Более выраженное действие депонированного препарата может быть связано с тем, что концентрация депонированного цитостатика в 
среде постепенно увеличивается и к 3-м суткам выход достигает 50-70 \% от исходного содержания. Между тем 5-фторурацил в традиционной лекарственной форме подавляет рост опухолевых клеток в меньшей степени. Скорее всего, это связано с тем, что 5-фторурацил в традиционной лекарственной форме утилизируется клетками или распадается в среде, в результате чего его концентрация со временем снижается и это приводит к снижению антипролиферативной активности препарата. Таким образом, этими результатами продемонстрирована эффективность цитостатического действия препарата, депонированного в микрочастицы из П(ЗГБ), по отношению к культуре опухолевых клеток линии HeLa.

\section{Заключение}

В работе получены микрочастицы из П(ЗГБ), содержащие противоопухолевый препарат 5-фторурацил. Показано, что применение метода распылительной сушки позволяет упростить технологию получения микрочастиц, содержащих лекарственные препараты. Изучена кинетика выхода 5-фторурацила из микрочастиц, показана эффективность их действия по отношению к опухолевым клеткам карциномы шейки матки. Результаты свидетельствуют о том, что пролонгированное высвобождение 5-фторурацила из микрочастиц на основе П(ЗГБ) происходит за счет диффузии лекарственного препарата из полимерного матрикса и приводит к подавлению пролиферации клеток карциномы шейки матки. Подавление пролиферации клеток тем эффективнее, чем больше содержание цитостатика в матриксе микрочастиц.

В целом показано, что применение метода распылительного высушивания позволяет получить полимерные микрочастицы, которые могут служить основой для создания новых лекарственных форм препаратов пролонгированного действия для лечения различных заболеваний, в том числе онкологических.

Работа выполнена за счет средств государственного задания на проведение фундаментальных исследований РАН (проект № гос. регистрации 01201351505).

\section{Список литературы}

Волова Т.Г., Гительзон И.И., Калачева Г.С., Кузнецов В.Н., Шабанов В.Ф. Патент РФ № 2207375 «Способ получения полимера $\beta$-оксимасляной кислоты». Заявка №201105608. Приоритет от 27.02.2001. Зарегистрировано в государственном реестре изобретений РФ 27.06.2003 [Volola T.G., Gitelson I.I., Kalacheva G.S., Kyznetsov V.N., Shababov V.F. Patent of Russian Federation. «The method of preparation of $\beta$-hydroxybutyric acid». Reference № 2207375, dated 27.02.2001. Application №201105608 (in Russian)]

Шершнева А.М., Шишацкая Е.И. (2014) Конструирование микрочастиц на основе резорбируемых полимеров «Биопластотан» с применением метода распылительной сушки. Журнал Сибирского федерального университета. Биология, 7 (2): 195-208 [Shershneva A.M., Shishatskaya E.I. Construction of microparticles based on resorbable polymers bioplastotan using spray drying method. Journal of Siberian Federal University. Biology [Zhurnal Sibirskogo federalnogo universiteta. Biologiya], 7 (2): 195-208 (in Russian)]

Ambruosi A., Gelperina S., Khalansky A. (2006) Influence of surfactants, polymer and doxorubicin loading on the anti-tumor effect of poly(butyl cyanoacrylate) nanoparticles in a rat glioma model. Journal of Microencapsulation, 23: 582-592 
Anchordoquy T.J., Koe G.S. (2000) Physical stability of nonviral plasmid-based therapeutics. J. Pharm. Sci., 89: 289-296

Bazzo G., Lemous-Senna M., Pires A. (2009) Poly(3-hydroxybutyrate)/Chitosan/ketoprofen or piroxicam composite microparticles: preparation and controlled drug release evaluation. Carbohydrate Polymers, 77: 839-844

Blanco M.D., Blanco R.L., Sastre C., Teljon N., Olmo R., Teljor M. (2005) 5-Fluorouracil-loaded microspheres prepared by spray-drying poly(D,L-lactide) and poly(lactide-co-glycolide) polymers: Characterization and drug release. Journal of Microencapsulation, 22 (6): 671-682

Burgess D.J. (2005) Injectable dispersed systems: formulation, processing, and performance. Nanoparticulate drug delivery system. Swarbrick J. (ed.) New York, Informa Healthcare, p. 39-65

Daugherty A.L., Mrsny R.J. (2006) Formulation and delivery issues for monoclonal antibody therapeutics. Adv. Drug Deliv. Rev., 58: 686-706

Embelton J.K., Tighe B.J. (1992) Polymers for biodegradable medical devices. IX: Microincapsulation studies: effects of polymers composition and process parameters on polyhydroxybutyrate-hydroxyvalerate microcapsule morphology. Biomaterials, 9: 73-87

Freitas S., Merkle H., Gander B. (2005) Microencapsulation by solvent extraction/evaporation: reviewing the state of the art of microsphere preparation process technology. Journal of Controlled Release, 102: 313-332

Goreva A.V., Shishatskaya E.I., Volova T.G., Sinskey A.J. (2012) Characterization of polymeric microparticles based on resorbable polyesters of oxyalkanoic acids as a platform for deposition and delivery of drugs. Polym. Sci. Ser. A, 54 (2): 94-105

Holland S., Yasin M., Tighe B. (1990) Polymers for biodegradable medical devices. VII. Hydroxybutyrate-hydroxyvalerate copolymers: degradation of copolymers and their blends with polysachrides under in vitro physiological conditions. Biomaterials, 11: 206-215

Jensen D.M., Cun D., Maltesen M.J., Frokjaer S., Nielsen H.M., Foged C. (2010) Spray drying of siRNA-containing PLGA nanoparticles intended for inhalation. J. Control. Release, 142: 138-145

Khang G., Kim S., Cho J., Yoon S., Lee H. (2001) Preparation and characterization of poly(3hydroxybutirate-co-3-hydroxyvalerate) microspheres for the sustained release of 5-fluorouracil. Biomed Mater Eng., 11: 89-103

Kolakovic R., Laaksonen T., Peltonenet L., Laukkanen A., Hirvonen J. (2012) Spray-dried nanofibrillar cellulose microparticles for sustained drug release. Int. J. Pharm., 430: 47-55

Lassalle V., Ferreira M. (2007) PLA nano- and microparticles for drug delivery: an overview of the methods of preparation. Macromol. Bioscience 7: 767-783

Lebrun P., Krier F., Mantanuset J., Grohganz H., Yang M., Rozet E., Boulanger B., Evrard B., Rantanen J., Hubert P. (2012) Design space approach in the optimization of the spray-drying process. Europ. J. Pharm. Biopharm., 80: 226-234

Livshits V. A., Bonartsev A. P., Iordanskii A. L., Ivanov E. A., Makhina T. A., Myshkina V. L., Bonartseva G. A. (2009) Microspheres based on poly(3-hydroxy)butyrate for prolonged drug release. Polymer Science Series B, 51 (7): 256-263

Mohajel N., Roholamini Najafabadi A., Azadmanesh K., Vatanara A., Moazeni E., Rahimi A., Gilani K. (2012) Optimization of a spray drying process to prepare dry powder microparticles containing plasmid nanocomplex. Int. J. Pharm., 423: 577-585 
Murueva A.V., Shishatskaya E.I., Kuzmina A.M., Volova T.G., Sinskey A.J. (2013) Microparticles prepared from biodegradable polyhydroxyalkanoates as matrix for encapsulation of cytostatic drug. J. Mater. Sci.: Mater. Med., 24: 1905-1915

Ohashi K., Takahiro K., Ozeki T., Okada H. (2009) One-step preparation of rifampicin/poly(lacticco-glycolic acid) nanoparticle-containing mannitol microspheres using a four-fluid nozzle spray drier for inhalation therapy of tuberculosis. Journal of Controlled Release, 135: 19-24

Palazzo F., Giovagnoli S., Schoubben A., Blasi P., Rossi C., Ricci M. (2013) Development of a spray-drying method for the formulation of respirable microparticles containing ofloxacin-palladium complex. International Journal of Pharmaceutics, 440: 273-282

Ramezani V., Vatanara A., Najafabadi A.R., Gilani K., Nabi-Meybodi M. (2013) Screening and evaluation of variables in the formation of antibody particles by spray drying. Powder Technology, 233: $341-346$

Shishatskaya E.I., Goreva A.V., Kalacheva G.S., Volova T.G. (2011) Biocompatability and resorption of intravenously administered polymer microparticles in tissue of internalorgans of laboratory animals. Journal of Biomater Sci Polym Ed., 22: 2185-2203

Shishatskaya E.I., Goreva A.V., Kuzmina A.M. (2013) Study of the efficiency of doxorubicin deposited in microparticles from resorbable bioplastotaneTM on laboratory animals with ehrlich's solid carcinoma. Bulletin of experimental biology and medicine, 154 (6): 773-777

Stulzer H., Tagliari M., Parize A., Silva M., Laranjeira M. (2009) Evaluation of cross-linked chitosan microparticles containing acyclovir obtained by spray-drying. Materials Science and Engineering C, 29: 387-392

Vehring R. (2008) Pharmaceutical particle engineering via spray drying. Pharmaceutical Research, 25 (5): 999-1022

Wang Y., Kho K., Cheow W.S., Hadinoto K. (2012) A comparison between spray drying and spray freeze drying for dry powder inhaler formulation of drug-loaded lipid-polymer hybrid nanoparticles. Int. J. Pharm., 424: 98- 106 